\title{
Involvement of ethylene receptors in the salt tolerance response of Cucurbita pepo
}

\author{
Gustavo Cebrián", Jessica Iglesias-Moya', Alicia García', Javier Martínez", Jonathan Romero', José Javier Regalado, \\ Cecilia Martínez', Juan Luis Valenzuela (D) and Manuel Jamilena (iD
}

\begin{abstract}
Abiotic stresses have a negative effect on crop production, affecting both vegetative and reproductive development. Ethylene plays a relevant role in plant response to environmental stresses, but the specific contribution of ethylene biosynthesis and signalling components in the salt stress response differs between Arabidopsis and rice, the two most studied model plants. In this paper, we study the effect of three gain-of-function mutations affecting the ethylene receptors CPETR1B, CPETR1A, and CPETR2B of Cucurbita pepo on salt stress response during germination, seedling establishment, and subsequent vegetative growth of plants. The mutations all reduced ethylene sensitivity, but enhanced salt tolerance, during both germination and vegetative growth, demonstrating that the three ethylene receptors play a positive role in salt tolerance. Under salt stress, etrib, etr $1 a$, and etr2b germinate earlier than WT, and the root and shoot growth rates of both seedlings and plants were less affected in mutant than in WT. The enhanced salt tolerance response of the etr2b plants was associated with a reduced accumulation of $\mathrm{Na}^{+}$in shoots and leaves, as well as with a higher accumulation of compatible solutes, including proline and total carbohydrates, and antioxidant compounds, such as anthocyanin. Many membrane monovalent cation transporters, including $\mathrm{Na}^{+} / \mathrm{H}^{+}$and $\mathrm{K}^{+} / \mathrm{H}^{+}$ exchangers (NHXs), $\mathrm{K}^{+}$efflux antiporters (KEAs), high-affinity $\mathrm{K}^{+}$transporters (HKTs), and $\mathrm{K}^{+}$uptake transporters (KUPs) were also highly upregulated by salt in etr2b in comparison with WT. In aggregate, these data indicate that the enhanced salt tolerance of the mutant is led by the induction of genes that exclude $\mathrm{Na}^{+}$in photosynthetic organs, while maintaining $\mathrm{K}^{+} / \mathrm{Na}^{+}$homoeostasis and osmotic adjustment. If the salt response of etr mutants occurs via the ethylene signalling pathway, our data show that ethylene is a negative regulator of salt tolerance during germination and vegetative growth. Nevertheless, the higher upregulation of genes involved in $\mathrm{Ca}^{2+}$ signalling (CPCRCK2A and $C p C R C K 2 B)$ and $A B A$ biosynthesis (CPNCED3A and CPNCED3B) in etr2b leaves under salt stress likely indicates that the function of ethylene receptors in salt stress response in $C$. pepo can be mediated by $\mathrm{Ca}^{2+}$ and $\mathrm{ABA}$ signalling pathways.
\end{abstract}

\section{Introduction}

One of the great challenges facing agriculture today is the development of production systems that mitigate the deleterious effects of climate change, including drought and salinity ${ }^{1}$. In arid and semi-arid areas, soil and water salinity constitute two of the most important abiotic

Correspondence: Manuel Jamilena (mjamille@ual.es)

'Department of Biology and Geology, Agri-food Campus of International Excellence (CeiA3) and Research Center CIAMBITAL, University of Almería, 04120 Almería, Spain stresses that limit crop production. At present, $>1$ billion hectares worldwide are affected by soil salinity ${ }^{2}$.

Crop development and performance is severely affected by salinity. The primary effects of salinity are very similar to those caused by drought. A high concentration of salt in the soil reduces the plant's ability to absorb water, known as the osmotic effect due to salinity. This not only leads to reduced absorption of essential elements, such as $\mathrm{K}^{+}, \mathrm{Ca}^{2+}$ and $\mathrm{NO}_{3}{ }^{-}$, but also a toxic accumulation of $\mathrm{Na}^{+}$ and $\mathrm{Cl}^{-}$in aerial parts of the plant ${ }^{3}$. The accumulation of salt in leaf cells inhibits cell expansion and photosynthetic

\section{(c) The Author(s) 2021}

(c) (i) Open Access This article is licensed under a Creative Commons Attribution 4.0 International License, which permits use, sharing, adaptation, distribution and reproduction c. in any medium or format, as long as you give appropriate credit to the original author(s) and the source, provide a link to the Creative Commons license, and indicate if changes were made. The images or other third party material in this article are included in the article's Creative Commons license, unless indicated otherwise in a credit line to the material. If material is not included in the article's Creative Commons license and your intended use is not permitted by statutory regulation or exceeds the permitted use, you will need to obtain permission directly from the copyright holder. To view a copy of this license, visit http://creativecommons.org/licenses/by/4.0/. 
activity, which ultimately leads to a reduction in crop yield $^{4}$.

The entrance and the perception of $\mathrm{Na}^{+}$in roots are little known processes. Sodium can enter the root through non-selective cation channels (NSCCs) ${ }^{5}$, although extracellular cation receptors, such as MONOCATION INDUCED $\left[\mathrm{Ca}^{2+}\right]$ and INCREASES 1 (MOCA1), have been detected, which are capable of sensing sodium and other cations, as well as promoting the influx of $\mathrm{Ca}^{2+}$ into the cell ${ }^{6,7}$. The perception of the stress signal triggers a secondary signalling by reactive oxygen species (ROS) and abscisic acid (ABA), which also regulate the intracellular level of $\mathrm{Ca}^{2+}$. The cytosolic calcium activates phosphorylation cascades of $\mathrm{Ca}^{2+}$-dependent proteins or calcium sensors, including calmodulins (CaM), CaM-like (CML) and calcineurin B-like proteins $(\mathrm{CBL})$, which leads to regulation of stress response genes ${ }^{8,9}$.

To deal with salinity, plants have implemented three general mechanisms that improve plant tolerance to salt stress: (i) restoration of ion homoeostasis $\left(\mathrm{Na}^{+} / \mathrm{K}^{+}\right.$ homoeostasis); (ii) restoration of osmotic homoeostasis; and (iii) prevention and repair of cell damage. Ionic homoeostasis mediated by membrane ion transporters constitutes the main response mechanism against salt stress. Plasma membrane $\mathrm{Na}^{+} / \mathrm{H}^{+}$antiporters, such SALT OVERLY SENSITIVE 1 (SOS1/AtNHX7) and AtNHX8, extrude $\mathrm{Na}^{+}$into the extracellular medium in response to an increase in intracellular $\mathrm{Ca}^{2+}$. $\mathrm{HIGH}$-AFFINITY $\mathrm{K}^{+}$ TRANSPORTER1-like (HTK1-like) also has a strong affinity for $\mathrm{Na}^{+9}$, which excludes the translocation of $\mathrm{Na}^{+10,11}$. Tonoplast $\mathrm{Na}^{+} / \mathrm{H}^{+}$antiporters, such as $\mathrm{Na}^{+} / \mathrm{H}^{+}$ EXCHANGER 1-4 of Arabidopsis (NHX1-4), are also activated by $\mathrm{Ca}^{2+}$, transporting $\mathrm{Na}^{+}$(and $\mathrm{K}^{+}$) into the vacuole ${ }^{12-14}$, reducing toxic $\mathrm{Na}^{+}$in the cytoplasm, and decreasing the osmotic potential of the cell. The overexpression of both plasma membrane and tonoplast antiporters results in a greater tolerance to salinity in a wide range of plant species ${ }^{15-17} . \mathrm{K}^{+}$transporters, including the high-affinity transporter family HAK/KT/ KUP, the HKT family of high-affinity $\mathrm{K}^{+}$transporters and the KEA family of $\mathrm{K}^{+}$efflux antiporters, are also involved in salt tolerance by maintaining $\mathrm{K}^{+} / \mathrm{Na}^{+}$homoeostasis $^{10,17}$. To restore osmotic homoeostasis and cell volume and turgor, salt also activates the production of compatible solutes or osmolytes, including proline, sugar alcohols, sorbitol and anthocyanins, among others ${ }^{18,19}$. These osmolytes also function as protectors of membranes and proteins by reducing oxidative damage $\mathrm{e}^{20,21}$.

The phytohormones ABA and ethylene play key roles in the defensive response of plants against abiotic stresses ${ }^{7,22}$. $\mathrm{ABA}$ is a positive regulator of plant defensive response. Under both salinity and water deficit, plants induce the production of ABA biosynthesis genes, such as NINE-CISEPOXYCAROTENOID DIOXYGENASES (NCEDS) and
$\mathrm{ABA}$ DEFICIENTS (ABAs). ABA is then perceived by the ABA receptors PYRABACTIN RESISTANCE/PYRABACTIN RESISTANCE LIKE (PYR/PYL), which induce phosphorylation activity of the ABA-dependent SUCROSE NON-FERMENTING RELATED PROTEIN KINASES (SnRKs) family, and the activation of the ABA-dependent transcriptional network involved in ionic and osmotic adjustments in response to salt stress ${ }^{7,23}$.

The function of ethylene in salt stress response is, however, more controversial ${ }^{24}$. It is generally presumed that ethylene improves the response of plants to salt stress $^{25}$. However, other authors supported a negative role of ethylene during salt stress, at least in certain growth stages in which its induction can activate oxidative stress and leaf senescence ${ }^{26}$. In Arabidopsis, ethylene positively regulates salinity response, and both ethylene biosynthesis and signalling genes are required for salt tolerance ${ }^{27,28}$. The biosynthesis $A C S$ and $A C O$ genes in Arabidopsis are induced under salinity conditions, but certain individual members can play a negative role in salt tolerance ${ }^{29-31}$. The ethylene signalling elements also participate in the response of plant to salt stress, but their functions are also unclear $^{24}$. In Arabidopsis, the positive elements of the ethylene response are generally upregulated in response to salt and are positive regulators of salt tolerance; whereas, negative elements are downregulated by salt and are considered to be negative regulators of salt tolerance $^{24}$. In contrast, orthologous ethylene positive signalling genes, including MHZ7/OsEIN2, MHZ6/OSEIL1 and OsEIL2, have an opposite function in rice, since their suppression produces salinity tolerance, while their individual overexpression enhances salt sensitivity ${ }^{32}$.

The five ethylene receptors of Arabidopsis, ETR1, ERS1, ETR2, ERS2 and EIN4, are negative regulators of the ethylene signal pathway, but play a contrasting role in salt tolerance. They possess highly similar amino acid sequences and domain structures. The ethylene binding property of all of the receptors resides in three or four Nterminal transmembrane helices that are located within the membrane of the endoplasmic reticulum ${ }^{33,34}$. These $\mathrm{N}$ domains are connected by a GAF domain to a C-terminal His protein kinase domain that is positioned in the cytoplasm $^{33,34}$. ETR1, ETR2, and EIN4 have an additional C-terminal receiver domain ${ }^{34}$. Both gain-of-function and loss-of-function mutants have been described for the five Arabidopsis ethylene receptor genes. Dominant gain-offunction mutations in a single receptor gene lead to ethylene insensitivity; whereas, recessive loss-of-function mutations confer little or no phenotype, but the combination of two or three loss-of-function ethylene receptor mutations confers constitutive ethylene responses ${ }^{35}$. The function of the five Arabidopsis ethylene receptor genes in salt tolerance has been investigated in loss-of-function mutants during germination, finding that ETR1 and EIN4 
inhibit, while ETR2 stimulates and ERS1 and ERS2 have no effect on, seed germination under salt stress $^{36-38}$. These contrasting roles do not appear to require an ethylene canonical signalling pathway, but occur by regulating ABA signal transduction ${ }^{24,25,36,39}$. Silencing of alfalfa MsETR2 abolishes ethylene-triggered tolerance to salt stress, indicating that this ethylene receptor is a positive regulator of salt tolerance in alfalfa ${ }^{40}$.

Recently, García et al. ${ }^{41}$ isolated four Cucurbita pepo mutants, etr1a, etr1a-1, etr $1 b$ and etr $2 b$, all exhibiting a reduced response to ethylene, as well as concomitant changes in developmental traits regulated by ethylene ${ }^{41-43}$. The four mutations affected sex determination in this monoecious species, as well as female fertility. They convert female into male or female-sterile hermaphrodite flowers, which prevents self-fertilisation of homozygous mutant plants, and forces the maintenance of mutations in segregating populations ${ }^{42,43}$. The duplicated genome of C. pepo ${ }^{44}$ contains six ethylene receptor genes, two paralogs for either ETR1 (CPETR1A and CpETR1B), ERS1 (CPERS1A and $C p E R S 1 B)$ and ETR2 (CpETR2A and CpETR2B), and the identified mutations affect three of the ethylene receptor genes. etr1a-1 and etr1a are A95V and P36L amino acid exchanges in the first and third transmembrane helix of CpETR1A, respectively, etr1b is a T94I amino acid exchange in the third transmembrane helix of CpETR1B, and $e t r 2 b$ is an E340K amino acid exchange in the coiledcoil domain between the GAF and histidine-kinase domains of CpETR2B ${ }^{42,43}$.

In this paper, we investigated the response of etr $1 b$, $e t r 1 a$, and $e t r 2 b$ gain-of-function mutants to salt stress during germination, seedling establishment, and subsequent vegetative growth. Since the three mutants showed enhanced salt tolerance response during all studied developmental stages and reduced content of $\mathrm{Na}^{+}$in photosynthetic organs, we also analysed the molecular mechanisms involved in the enhanced salt tolerance of the Cucurbita etr mutants, including accumulation of osmoprotectants and activation of gene networks involved in the biosynthesis of $\mathrm{ABA}, \mathrm{Ca}^{2+}$ signalling elements, and $\mathrm{Na}^{+}$and $\mathrm{K}^{+}$membrane transporters reducing the accumulation of toxic $\mathrm{Na}^{+}$in shoots and leaves.

\section{Results}

Tolerance of etr $1 b$, etr $1 a$, and etr $2 b$ to salt stress during germination and early stages of seedling development

To determine the ability of etr mutants to germinate in the presence of $\mathrm{NaCl}, \mathrm{WT}$ and etr $1 b$, etrla, and etr $2 b$ mutant seeds were germinated in both water and $100 \mathrm{mM}$ of $\mathrm{NaCl}$ up to $55 \mathrm{~h}$, recording the initiation of seed germination every $2 \mathrm{~h}$. The results are shown in Fig. 1. In water, both WT and the three etr mutants showed a similar germination rate, although the mutant seed was slightly delayed with respect to WT (Fig. 1A). The $\mathrm{NaCl}$ treatment delayed germination of both WT and etrs, but the delayed time was much higher in the WT, meaning that the three etr mutants germinated faster than WT under salt stress.

The salt treatment affected WT and mutant seed differently for different germination parameters, including germination initiation, average time for $50 \%$ germination, and average germination time (Fig. 1B, D). In water, the assessment of the three germination parameters in etr seeds was highly similar to that of WT. Under salt stress, however, there was a significant increase in germination initiation, $50 \%$ of germination and average germination time in WT and mutant seeds, but the percentage of increase of these three parameters in $\mathrm{NaCl}$ with respect to water was significantly lower in the three mutants compared with their corresponding WT genotypes (Fig. 1B). Taken together, the data revealed that the three etr mutants are all more tolerant to salt stress than their corresponding WT during germination.

Seedling growth was also differentially reduced by salinity in WT and ethylene-insensitive mutants (Fig. 2). Radicle and hypocotyl growth rates were both reduced in response to $\mathrm{NaCl}$ treatments in WT and etr mutants, but the mutant seedlings were always less affected than WT ones (Fig. 2). When germinated and grown in water, the length of the radicle $48 \mathrm{~h}$ after germination was similar in WT and mutants, but the reduction of the radicle length under salt stress conditions was much more noticeable in the WT seedlings (Fig. 2A). The same was true for the length of the hypocotyl 3 days after germination, a parameter that was much more reduced in WT than in etr mutants (Fig. 2B). Under salt stress, in fact, WT seedlings reduced the length of their hypocotyls by approximately $50 \%$, while etr mutants exhibited a reduction of only 20-35\% (Fig. 2A, B).

Figure 3A, B shows the effect of salt stress on the root and shoot growth, and root balls of WT and etr mutants, 20 days post-germination. Under control conditions, the root and leaf biomass of mutant seedlings was much higher than that of WT, indicating a higher vigour in the three mutant plants (Fig. 3C, D). Although root biomass was decreased considerably under salt stress, that of mutant plants was similar to that of the WT control plants grown in water (Fig. 3C). The biomass of the aerial part of the plant was also significantly higher in the etr mutants, and although reduced by the $\mathrm{NaCl}$ treatment, the leaf biomass of the mutant plants under salt stress was also higher than that of the WT (Fig. 3D). The reduction in leaf and root biomass in response to salt stress was not significantly different between WT and mutant plants (Fig. 3C, D). These data demonstrate that etr1b, etrla and $e t r 2 b$ seedlings were more vigorous than those of WT under control and salt conditions, but the responsiveness of WT and mutant plants to salt stress did not 

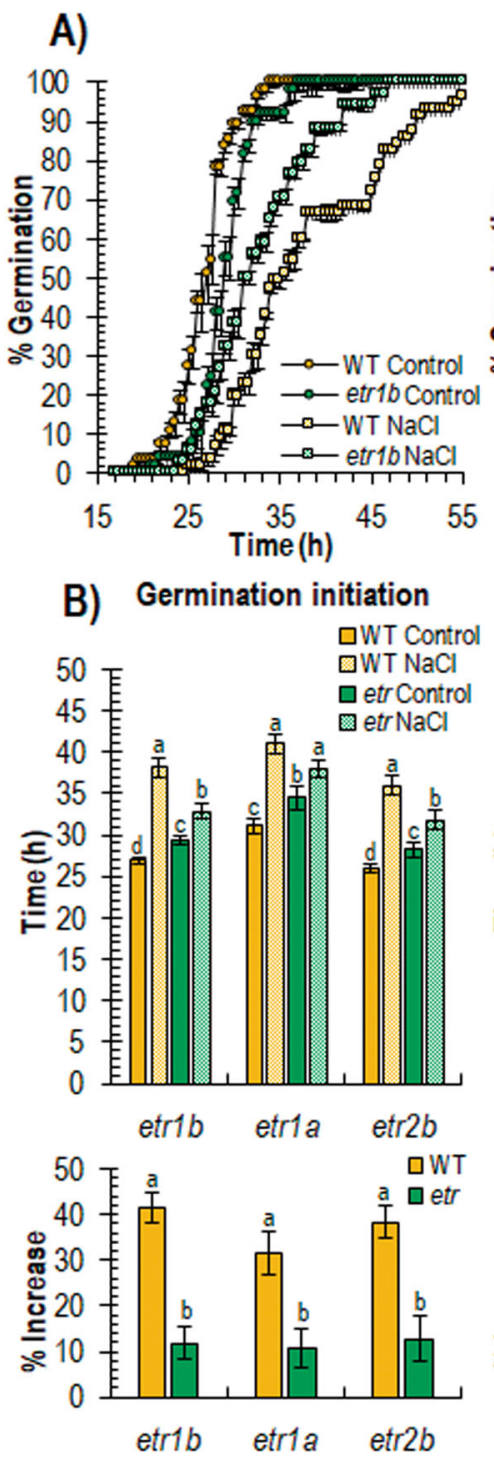

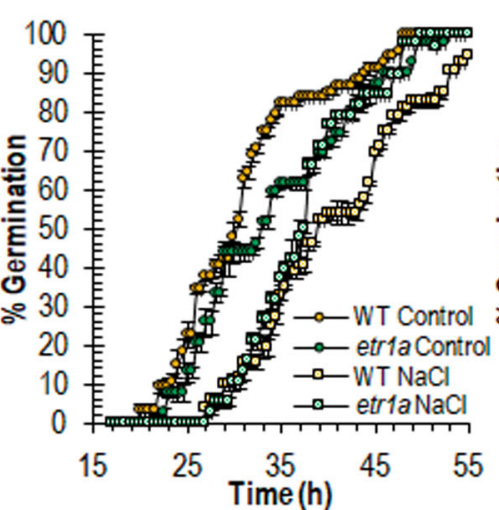

C) Time for $50 \%$ germination
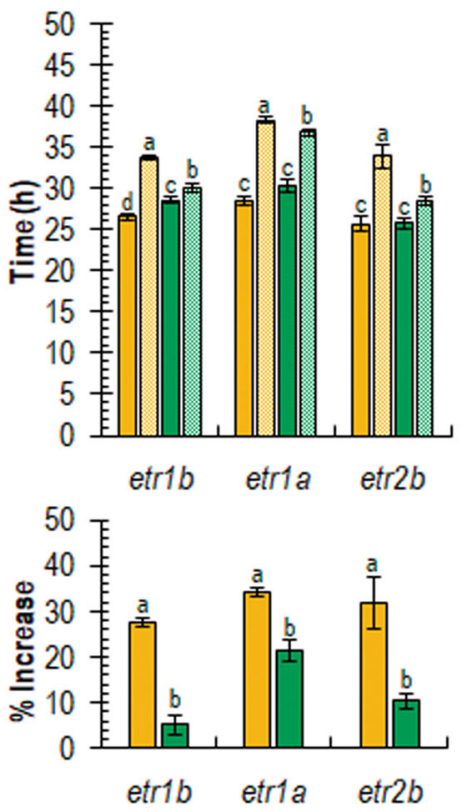

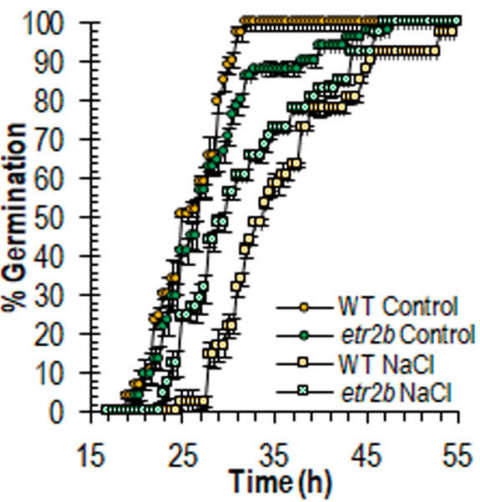

D) Average germination time

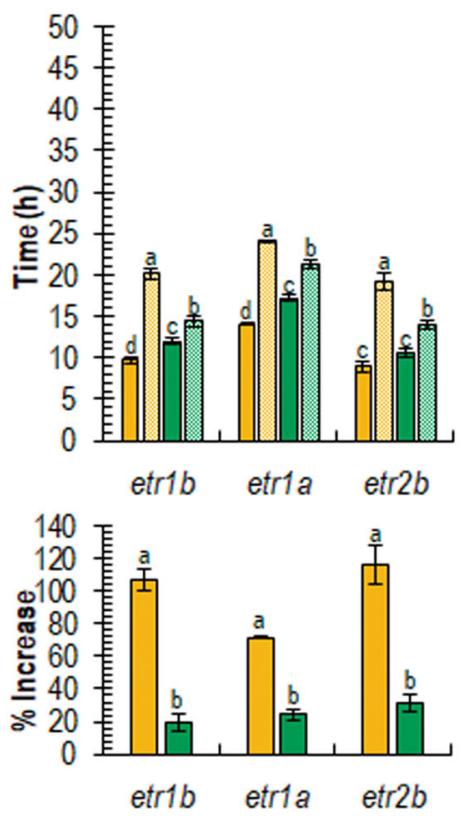

Fig. 1 Effect of salt stress on germination parameters of WT and etr $1 \boldsymbol{b}$, etr $1 \boldsymbol{a}$, and etr $\mathbf{2 b}$. A Germination rates of WT and etr $1 b$, etr $1 a$, and etr $2 b$ ethylene receptor mutants under control and $\mathrm{NaCl}$ conditions. The percentage of germination was analysed every $2 \hat{\mathrm{a}} \%$ oh at the indicated time points. The data represent means of three independent replicates with at least 50 seeds counted per replicate. $\mathbf{B}, \mathbf{C}$, and $\mathbf{D}$ Effect of $\mathrm{NaCl}$ stress treatment on germination initiation, time at which $50 \%$ of seed is germinated, and average germination time. The bottom graphs show the percentage of increase of each parameter in response to salt stress in WT and mutant plants with respect to plants of the same genotype grown under control conditions. Means were obtained from four independent replicates with at least 50 seeds per replicate. Different letters indicate statistically significant differences (Pâ€\%o<â€\%00.05) between samples

significantly differ, at least during the first 20 days of vegetative development.

\section{Growth and ionic balance of WT and etr2b plant in response to salt stress}

The separation of WT and etr $2 b$ offspring (see Materials and Methods) allowed further analyses of this ethylene receptor mutant. WT and $e t r 2 b$ plants were grown under control and saline conditions up to 45 days after sowing (DAS) (Fig. 4).
The growth of roots, shoots and leaves was always higher in the mutant (Fig. 4) under both control and salt stress, which confirmed the higher vigour of the ethylene receptor mutants observed in previous experiments, and the higher salt tolerance of the mutant. However, the relative response of WT and mutant plants to salt stress differed throughout plant development. At early stages (5 and 10 DAS) etr2b and WT responded similarly to salt stress, reducing both plant height and root length (Fig. 4A, B). The reduction in leaf and root biomass 


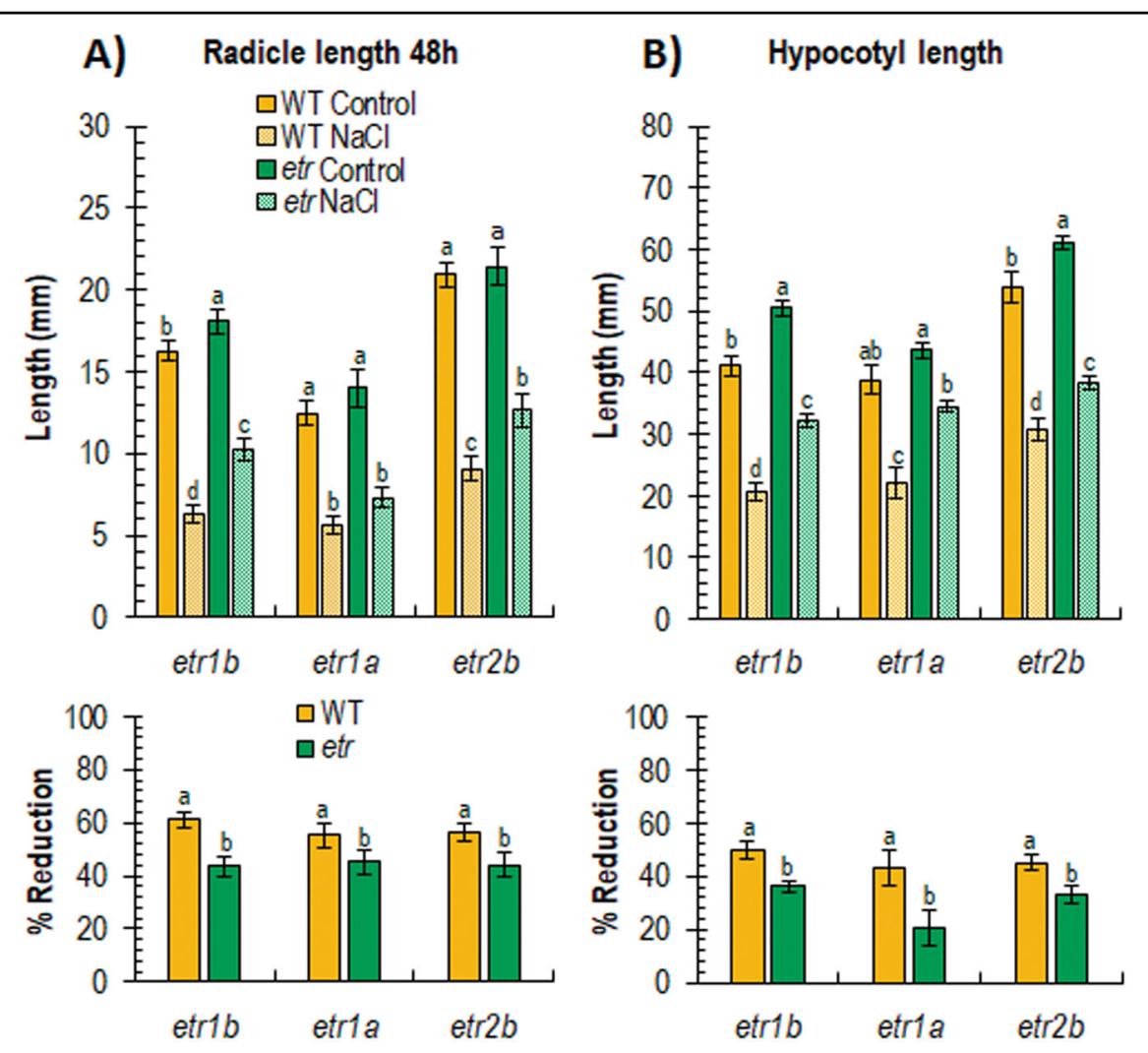

Fig. 2 Effect of salt stress on growth parameters of WT and etr $1 \boldsymbol{b}$, etr $1 \boldsymbol{a}$, and $\boldsymbol{e t r} \mathbf{2} \boldsymbol{b}$ seedlings. A Effect of salt stress on radicle length at $48 \mathrm{~h}$. B Effect of salt stress on hypocotyl length in seedlings growing in darkness for $72 \mathrm{~h}$. The bottom graphs of each figure show the percentage of reduction of each parameter in response to salt stress in WT and mutant plants with respect to plants of the same genotype growing under control conditions. Different letters indicate statistically significant differences $(P<0.05)$ between samples

between 5 and 30 DAS was also similar in WT and mutant plants (Fig. 4C, D). At 45 DAS, however, the salt sensitivity of the mutant was significantly lower than that of the WT, with etr2b exhibiting a significantly lower percentage of reduction in leaf and root biomass than WT (Fig. 4C, D). These data indicate that etr $2 b$, and probably the other two ethylene receptor mutants, have an enhanced tolerance to salt stress not only during germination, but also during plant vegetative development.

Table 1 shows the effect of salinity on the nutrient content of WT and etr $2 b$ leaves and roots. For most of the nutrients, no significant differences were found between WT and etr2 $b$ plants in either roots or in leaves. For $\mathrm{K}$ and $\mathrm{Ca}$, no differences were identified between WT and etr $2 b$, except that the Ca content was slightly lower in the mutant under non-saline conditions. The total $\mathrm{N}$ content was reduced in response to salt stress in both WT and mutant leaves, but no difference was detected between the response of the two genotypes. As expected, salt-stressed plants increased their content of the phytotoxic elements $\mathrm{Cl}^{-}$and $\mathrm{Na}$. In leaves of salt-stressed plants, $\mathrm{Na}$ accumulated at least $4.5 \mathrm{mg} / \mathrm{kg}$ more in WT than in etr $2 b$, but $\mathrm{Cl}^{-}$content was found to be similar in the two genotypes. In roots, however, no significant difference was found between WT and etr $2 b$ for either $\mathrm{Na}$ or $\mathrm{Cl}^{-}$(Table 1).

\section{Comparison of stress metabolites and gene expression in WT and etr $2 b$ in response to salt stress}

To gain insight into the mechanisms that regulate the enhanced salt tolerance of etr $2 b$, the content of some metabolites and the expression of genes related to salt stress in different plant systems were measured. Figure 5 shows the contents of proline, total carbohydrate, and anthocyanin in leaves and roots of WT and mutant plants grown under either control or salinity conditions for 45 days. Under control conditions, most of the assessments were similar in WT and etr $2 b$ plants, although etr $2 b$ roots showed a decreased content of proline, and $e t r 2 b$ leaves reduced their content in total carbohydrates (Fig. 5). In salt-stressed plants, the response of WT and mutant plants was completely dissimilar. Salt induced the accumulation of proline, total carbohydrates and anthocyanins in both roots and leaves of the mutant plants, but hardly changed their contents in WT in either roots or in leaves (Fig. 5A-C). 


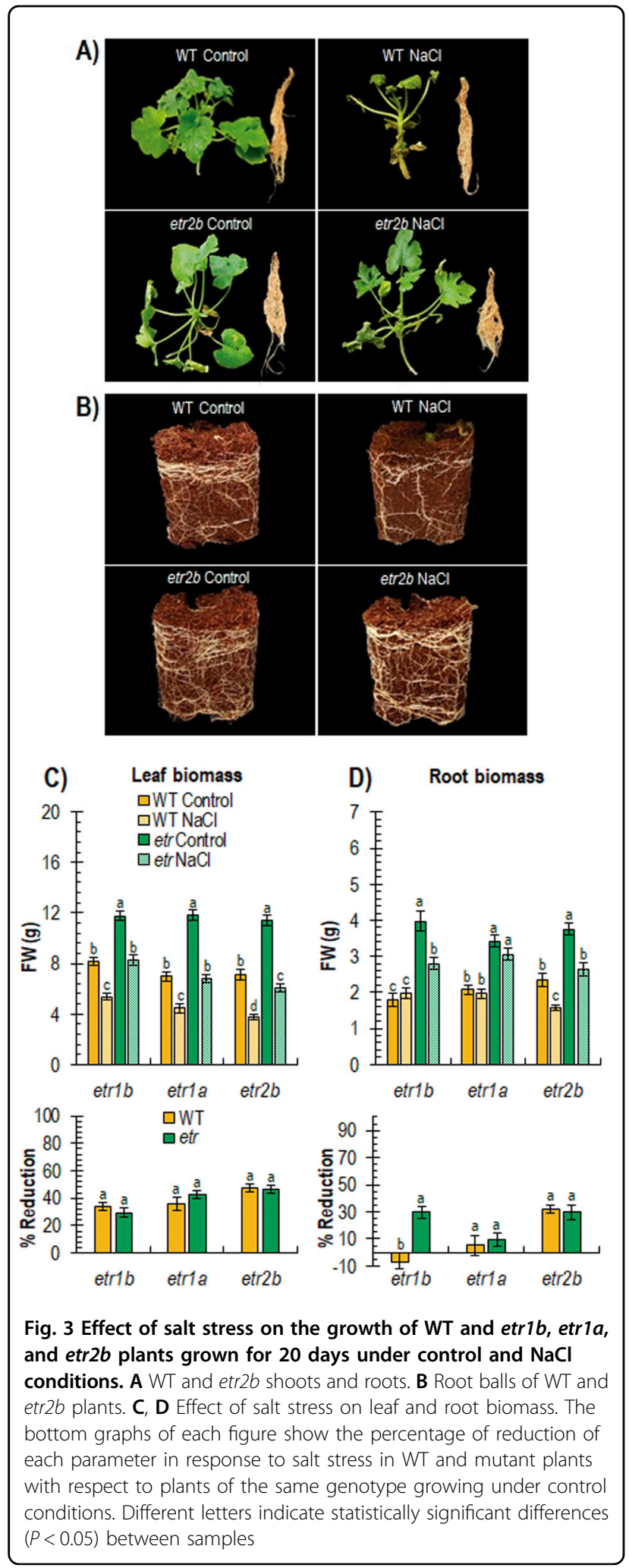

The expression of genes associated with abiotic stress tolerance was also compared in WT and etr2b plants grown over 45 days under standard and saline stress conditions. Since the C. pepo genome is duplicated, we investigated the expression of paralogs from both $A$ and $B$ subgenomes (indicated by the letter A or B at the end of the gene name, respectively). The phylogenetic relationship between $C$. pepo selected genes (Supplementary Table S2) and Arabidopsis homologues with known functions was previously examined for each gene family (Supplementary Fig. S2), thus providing a likely function of the analysed genes in C. pepo. In fact, the name that we assigned to each C. pepo gene corresponds to the Arabidopsis gene, which had the most conserved protein identity (Supplementary Fig. S2).

The expression of most of the genes associated with salt tolerance was much more induced in the mutant than in the WT plants, indicating an enhanced response of etr $2 b$ plants to salt stress (Fig. 6). $\mathrm{K}^{+}$transporter genes, including $\mathrm{K}^{+}$uptake permeases or KUPs (CpKUP6-1A, CpKUP6-1B and CpKUP6-2A, CpKUP6-2B), and $\mathrm{K}^{+} / \mathrm{H}^{+}$efflux antiporters or KEAs (CpKEA4-1A, CpKEA4-1B and CpKEA42A, CpKEA4-2B), with the exception of $C p K U P 6-2 A$, were upregulated by $\mathrm{NaCl}$ in both WT and etr $2 b$, but the upregulation in the mutant was between 2 and 25 times higher than in the WT (Fig. 6A, B). Under control conditions, some of them, including, CPKEA4-1A, CpKEA4-1B, were also more expressed in mutant than in WT plants.

The same is true for genes encoding $\mathrm{Na}^{+} / \mathrm{H}^{+}$exchanger $C p N H X 1-3 B$ and $\mathrm{Na}^{+}$transporter $C p H K T 1 A$, which were only upregulated in $e t r 2 b$ plants when grown under saline conditions (Fig. 6C). Of particular interest is the CPHKT1A gene, whose expression was already highest in non-stressed mutant plants, and was upregulated more than 300 -fold in response to salinity in only the etr $2 b$ mutant (Fig. 6C). Genes involved in abiotic stress signalling pathways, including $\mathrm{Ca}^{2+}$ signalling gene Calmodulin-binding receptor-like kinases $C p C R C K 2 A$ and $C p C R C K 2 B$, and ABA biosynthesis genes CPNCED3A and CPNCED3B, were also more highly induced in $e$ tr $2 b$ plants than in WT in response to salt stress (Fig. 6D, E).

\section{Discussion}

Ethylene is a key modulator of plant response to salt stress, but its specific role in different plant species and plant developmental stages is unclear ${ }^{24,27,32}$. In Arabidopsis and other plants, including maize and tomato, ethylene positively regulates salt stress tolerance $\mathrm{e}^{25,45-47}$, however, in other plant species, such as rice and tobacco, ethylene plays a negative role in salinity stress respons $\mathrm{e}^{24,32}$. In this paper, we demonstrate that ethylene is also involved in the salt stress response of C. pepo. All of the physiological and molecular data presented in this paper indicate that gain-of-function mutations in three C. pepo ethylene receptor genes increase salt stress tolerance at germination and during seedling and plant vegetative development, suggesting that ethylene is a negative regulator of salt tolerance in C. pepo. 

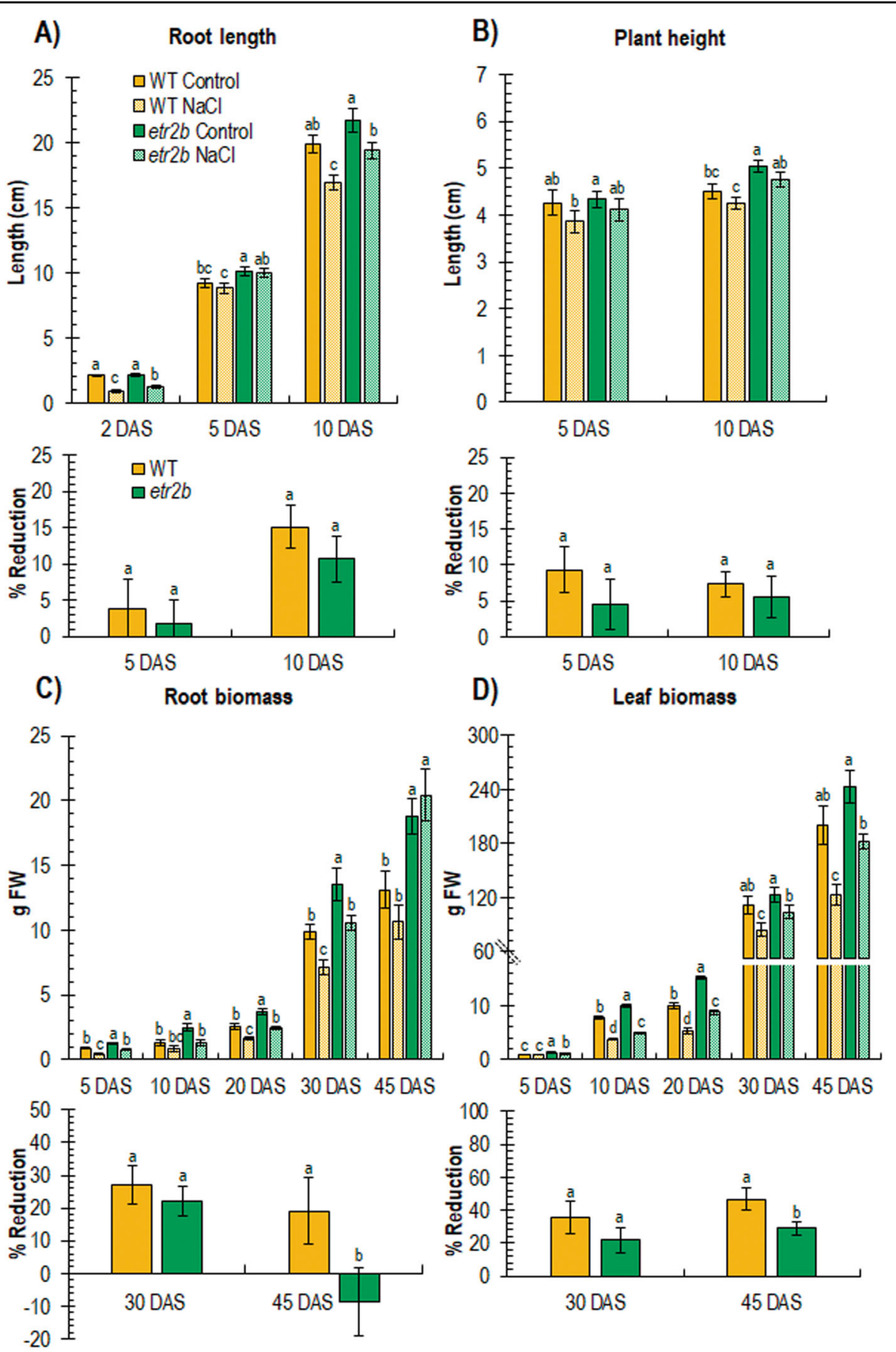

Fig. 4 Effect of salt stress on root and leaf development of WT and ethylene receptor etr2b mutant of $C$. pepo at different days after sowing (DAS). The graphs at the top in $\mathbf{A}, \mathbf{B}, \mathbf{C}$ and $\mathbf{D}$ show the growth rates of root length and plant height, as well as root and leaf biomass, in plants growing under control and $\mathrm{NaCl}$ conditions. The graphs at the bottom show the percentage of reduction of the same parameters in response to salt stress in WT and mutant plants with respect to plants growing under control conditions. Different letters indicate statistically significant differences $(P<0.05)$ between samples

ETR receptors modulate salt tolerance response at germination and during seedling and plant vegetative growth

Seed germination is severely affected by salinity, being the first process involved in the stress tolerance response ${ }^{7}$.
The phenotypes of loss-of-function mutants in Arabidopsis have demonstrated that ETR1 and EIN4 inhibit, while ETR2 enhances, seed germination under salt stress, and ERS1 and ERS2 have no significant effect on seed 
Table 1 Content of macronutrients, micronutrients, and phytotoxic elements in WT and etr2b mutant leaves and roots of plants grown under Control and $\mathrm{NaCl}$ conditions for a total of 45 days after sowing (DAS)

\begin{tabular}{|c|c|c|c|c|c|c|c|c|c|c|c|c|c|}
\hline & \multicolumn{6}{|c|}{ Macronutrients (\%) } & \multicolumn{5}{|c|}{ Micronutrients $(\mathrm{mg} / \mathrm{kg})$} & \multicolumn{2}{|c|}{$\begin{array}{l}\text { Phytotoxic } \\
\text { elements } \\
\text { (mg/kg) }\end{array}$} \\
\hline & $\mathrm{N}$ total & $\mathbf{P}$ & K & $\mathrm{Ca}$ & Mg & S & $\mathrm{Fe}$ & $M n$ & $\mathrm{Cu}$ & $\mathrm{Zn}$ & B & $\mathrm{Cl}^{-}$ & $\mathrm{Na}$ \\
\hline \multicolumn{14}{|l|}{ Leaves } \\
\hline WT control & $5.23 \mathrm{a}$ & $1.40 \mathrm{a}$ & $7.19 a$ & $4.16 \mathrm{ab}$ & $0.50 \mathrm{a}$ & $0.38 \mathrm{a}$ & 187.67 a & $202.33 \mathrm{a}$ & $5.91 \mathrm{C}$ & $77.73 \mathrm{~b}$ & $131.33 \mathrm{a}$ & $45.85 \mathrm{C}$ & $1.92 \mathrm{c}$ \\
\hline WT $\mathrm{NaCl}$ & $4.54 \mathrm{C}$ & $1.20 \mathrm{a}$ & $6.85 a$ & $4.06 \mathrm{ab}$ & $0.44 a$ & $0.39 a$ & 245.33 a & 219.67 a & 15.73 a & $100.20 \mathrm{a}$ & 117.67 a & $86.05 \mathrm{a}$ & $14.19 \mathrm{a}$ \\
\hline etr2b control & $5.08 \mathrm{~b}$ & $1.54 \mathrm{a}$ & $8.24 \mathrm{a}$ & $3.72 b$ & $0.43 a$ & $0.40 \mathrm{a}$ & $235.00 \mathrm{a}$ & $220.33 a$ & $6.69 c$ & $85.23 \mathrm{ab}$ & $125.50 \mathrm{a}$ & $63.71 \mathrm{~b}$ & $1.76 \mathrm{c}$ \\
\hline etr2b NaCl & $4.56 \mathrm{C}$ & $1.18 \mathrm{a}$ & $7.23 \mathrm{a}$ & $4.50 \mathrm{a}$ & $0.46 a$ & $0.38 \mathrm{a}$ & 199.67 a & 240.33 a & $10.10 \mathrm{~b}$ & $86.80 \mathrm{ab}$ & $110.00 \mathrm{a}$ & $82.73 \mathrm{a}$ & $9.61 \mathrm{~b}$ \\
\hline \multicolumn{14}{|l|}{ Root } \\
\hline WT control & $3.23 \mathrm{~b}$ & $1.66 \mathrm{a}$ & $2.00 \mathrm{a}$ & $1.47 \mathrm{a}$ & $0.17 a$ & $0.28 \mathrm{a}$ & $319.00 \mathrm{a}$ & $165.67 \mathrm{~b}$ & $8.29 b$ & $69.23 \mathrm{ab}$ & $33.80 a b$ & $7.37 b$ & $7.32 b$ \\
\hline $\mathrm{WT} \mathrm{NaCl}$ & $3.19 b$ & $1.32 \mathrm{c}$ & $2.40 \mathrm{a}$ & $0.81 \mathrm{~b}$ & $0.16 a$ & $0.33 \mathrm{a}$ & $292.00 \mathrm{a}$ & $212.50 \mathrm{ab}$ & $8.57 \mathrm{ab}$ & $59.85 b$ & $30.35 b c$ & $20.78 \mathrm{a}$ & $13.92 \mathrm{a}$ \\
\hline etr2b control & $3.29 a b$ & $1.58 \mathrm{ab}$ & $2.35 \mathrm{a}$ & $1.27 \mathrm{ab}$ & $0.16 a$ & $0.33 a$ & 312.33 a & $178.00 \mathrm{~b}$ & $9.28 \mathrm{ab}$ & $62.77 \mathrm{ab}$ & $35.47 \mathrm{a}$ & $10.76 b$ & $8.32 b$ \\
\hline etr2b $\mathrm{NaCl}$ & $3.47 \mathrm{a}$ & $1.41 \mathrm{bc}$ & $2.33 a$ & $1.12 a b$ & $0.16 a$ & $0.33 a$ & 289.67 a & $232.00 \mathrm{a}$ & $10.95 \mathrm{a}$ & $76.50 \mathrm{a}$ & $30.33 c$ & $18.82 \mathrm{a}$ & $12.91 \mathrm{a}$ \\
\hline
\end{tabular}

Different letters within the same column indicate significant differences between means $(P<0.05)$

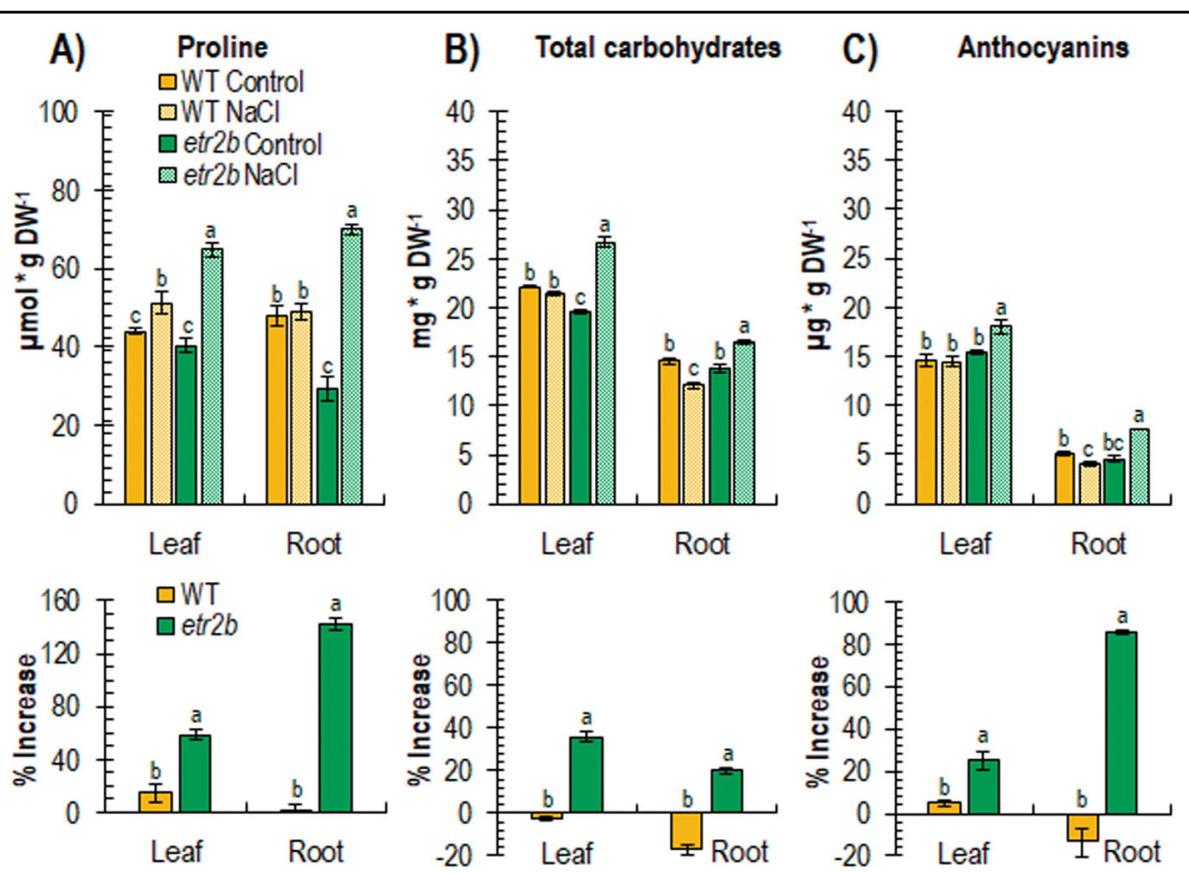

Fig. 5 Content of stress metabolites in WT and etr2b mutant leaves of plants growing under control and NaCl conditions for a total of $\mathbf{4 5}$ days after sowing (DAS). A, B and $\mathbf{C}$ shows the content of proline, total carbohydrates and anthocyanins, respectively. The bottom graphs show the increment in metabolite content in response to salt stress in WT and mutant plants. DW, dry weight. Different letters indicate statistically significant differences $(P<0.05)$ between samples

germination $^{36,37,39}$. Accordingly, Arabidopsis loss-offunction mutations for ETR1, including etr1-6 and etr17 , are more tolerant to salt stress and germinate before WT; whereas, gain-of-function mutants for ETR1, including etr1-1, etr1-2 and etr1-3, are more sensitive to salt stress and germinate later than WT under salt stress $^{48-50}$. The accelerated germination of the three analysed gain-of-function etr1b, etr1a, and etr $2 b$ of $C$. pepo under salt stress indicate that CPETR1B, CpETR1A, and CPETR2B are positive regulators of squash seed germination under salt stress. If this function is dependent on ethylene and the ethylene signal transduction pathway, ethylene would play a negative role in C. pepo salt tolerance, which is similar to what occurs in rice ${ }^{24}$. However, given that in Arabidopsis the function of ETRs in seed germination can take place independently of the canonical 


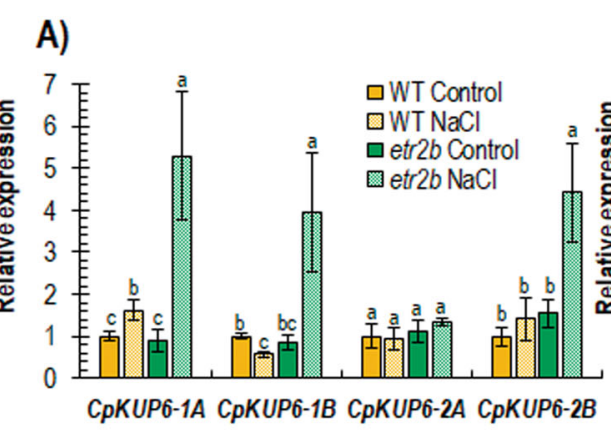

B)
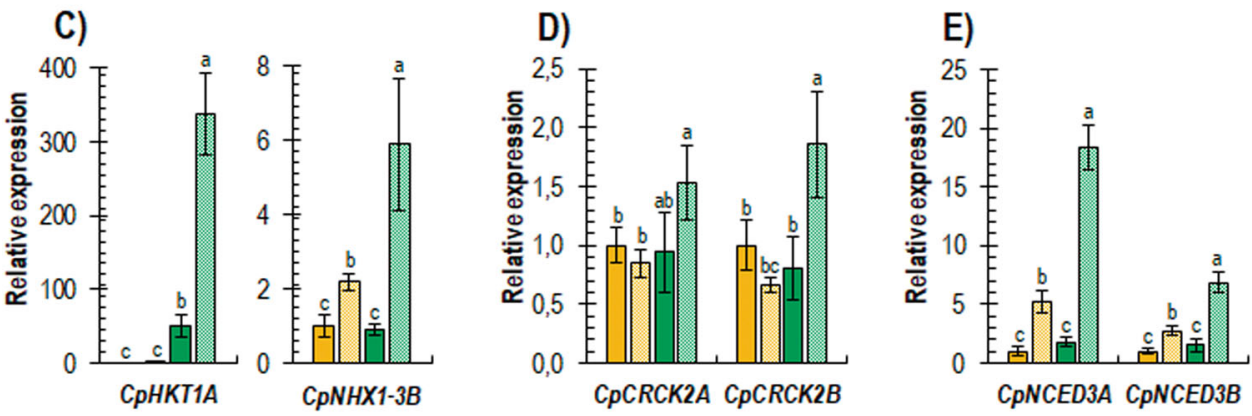

Fig. 6 Relative expression of genes encoding for ion transporters, salt stress signalling and ABA biosynthesis in leaves of WT and etr2b plants grown for $\mathbf{4 5}$ days under control and $\mathbf{~ N a C l}$ conditions. A Potassium transporters CpKUPs. B K+/H+ efflux antiporters CpKEAs. C Sodium transporter CpHKT1A and Na+/H+ exchanger CpNHX1-3B. D Calmodulin-binding receptor-like cytoplasmic kinase, CpCRCKs. E 9-cisepoxycarotenoid dioxygenase CPNCEDs, involved in ABA biosynthesis. In each gene family, the number of each gene corresponds to that of Arabidopsis with the highest identity at the protein sequence level, and the A and B letters at the end of each gene corresponds to paralogs derived from the $A$ and $B$ subgenomes of $C$. pepo, respectively. The relative level of each transcript was assessed by qRT-PCR in three independent replicates and normalised by the $\triangle \Delta C T$ method. Different letters indicate statistically significant differences $(P<0.05)$ between samples

ethylene signal transduction pathway, but appears to be mediated by ABA signalling ${ }^{36,39}$, it is also likely that the mechanisms underlying the function of squash ETRs under salt stress may also occur through ABA rather than the ethylene signalling pathway. The fact that the three etrs exhibit similar salt stress tolerance, but differ in the magnitude of their ethylene response (etr $1 b$ showed the most residual responsiveness and $\operatorname{etr} 2 b$ the least ${ }^{43}$ ), suggests that the function of $C$. pepo ETRs on germination under salt stress could take place independently of ethylene. The reduced germination rate of ethylene-insensitive etr mutants in water may also be the consequence of an increased biosynthesis or sensitivity to ABA, as found in Arabidopsis ethylene-insensitive mutants etr 1 and $\operatorname{ein} 2^{51}$. Furthermore, the higher induction of the ABA biosynthesis genes $C P N C E D 3 A$ and $C P N C E D 3 B$ in etr $2 b$ plants under salt stress also supports the involvement of $A B A$ in the salt tolerance of this mutant. The assessment of ABA sensitivity and ABA biosynthesis of C. pepo etr mutants in the presence and the absence of $\mathrm{NaCl}$ will provide insight into the interactions between $\mathrm{ABA}$ and ethylene signalling cascades during seed germination.

We also observed that the three C. pepo etr mutations promote seedling and plant growth, resulting in higher plant height, and higher root and leaf biomass when grown under control standard conditions. This higher vegetative vigour of etr mutants was also identified in adult plants ${ }^{42,43}$, indicating that ethylene is a negative regulator throughout the vegetative development cycle of the plant. The stimulating effect of ethylene insensitivity on vegetative growth was also found in Arabidopsis ethyleneinsensitive gain-of-function mutants ${ }^{49,52,53}$, although other studies found no differences in total leaf area between WT and the etr1-1 mutant at earlier stages of vegetative development ${ }^{54}$. The higher constitutive growth and vigour of squash ethylene-insensitive mutants was correlated with their higher salt tolerance during seedling and vegetative plant development. These data contrast with those found in Arabidopsis, in which the higher vegetative growth of the ethylene-insensitive gain-of-function etr1-1 mutant and the transgenic Arabidopsis plants overexpressing the tobacco ethylene receptor NTHK1 were associated with a higher salt sensitivity, while the reduced seedling growth of the etr1-7 loss-of-function mutant was associated with greater salt tolerance ${ }^{49,55}$. The reduced ABA sensitivity of etr1-7 and the enhanced ABA sensitivity of etr1-1 may account for differences in plant growth and salt-tolerance, as explained for germination ${ }^{49,51}$. 
The enhanced salt tolerance of C. pepo etrs during seedling and plant vegetative growth could result from the inhibitory role of ethylene receptors in the ethylene signalling pathway ${ }^{42,43}$. However, it is also likely that the vegetative growth regulation of ethylene receptors occurs through the abscisic acid signalling pathway, as has been observed for ETRs and EIN2 in Arabidopsis ${ }^{49,51,56}$. Genes involved in both ABA biosynthesis and intracellular $\mathrm{Ca}^{2+}$ signalling pathway were more induced in the mutant than in WT, which indicates that these two signalling pathways can coordinate the tolerance response of etr $2 b$ to salt stress. ABA is known to control the expression of ion transport genes and the influx of $\mathrm{Ca}^{2+}$ in the guard cells that leads to stomata closure limiting water loss in leaves ${ }^{57,58}$, but also a number of ABA responsive genes that are involved in ion homoeostasis and osmotic adjustment ${ }^{59}$.

\section{Mechanisms of salt tolerance in C. pepo etr mutants}

A number of physiological and molecular responses, including $\mathrm{Na}^{+}$detoxification, ion homoeostasis, osmotic adjustment and ROS scavenging, have been developed in plants to combat salt stress ${ }^{7}$. The exclusion of $\mathrm{Na}^{+}$in photosynthetic organs is a mechanism that is widely used by salt-tolerant genotypes to maintain vegetative growth while dealing with the high toxicity of these elements in leaves ${ }^{3}$. In our experiments, the leaves of the salt-stressed WT plant accumulated seven times more $\mathrm{Na}$ than nonstressed plants, but the leaves of the salt-tolerant etr $2 b$ only accumulated 5.3 more Na. Given that WT and etr $2 b$ roots have similar $\mathrm{Na}$ content, these data demonstrate a high ability of the salt-tolerant mutant to restrict the transport of $\mathrm{Na}^{+}$from roots to leaves.

The exclusion of $\mathrm{Na}^{+}$and the higher growth rates of etr $2 b$ plants are likely to be regulated by the induced $\mathrm{Na}^{+}$ and $\mathrm{K}^{+}$transporter genes in the leaf. As occurs with Arabidopsis AtNHX1 and AtNHX2 $\mathrm{Na}^{+} / \mathrm{H}^{+}$antiporters in the tonoplast, the induced $C p N H X 1-3 B$ may be involved in sequestering $\mathrm{Na}^{+}$into the vacuole, thus reducing the content of $\mathrm{Na}^{+}$in the cytoplasm and alleviating osmotic stress ${ }^{60,61}$. They also function as $\mathrm{K}^{+} / \mathrm{H}^{+}$ antiporters to maintain $\mathrm{K}^{+}$homoeostasis ${ }^{13}$. The CpHTK1A transporter is particularly interesting because it was upregulated 300 times more in etr $2 b$ than in WT. HTKs are high-affinity transporters for both $\mathrm{Na}^{+}$and $\mathrm{K}^{+}$, mediating root $\mathrm{Na}^{+}$uptake, $\mathrm{Na}^{+}$unloading from xylem sap, and leaf $\mathrm{Na}^{+}$refluxing to the phloem, which are mechanisms that increase leaf $\mathrm{Na}^{+}$exclusion ${ }^{62-65}$.

Gene expression data also suggest a positive role of the $\mathrm{K}^{+}$transporters KEAs and KUPs in combating salt stress. The Arabidopsis KEAs are $\mathrm{K}^{+} / \mathrm{H}^{+}$antiporters that mediate $\mathrm{pH}$ and $\mathrm{K}^{+}$homoeostasis in the inner and thylakoid membranes of chloroplast (KEA1, KEA2, and KEA3) or in endomembrane compartments (KEA4, KEA5, and
KEA6 $)^{66,67}$. The C. pepo KEAs genes that were highly induced in $e t r 2 b$ under salt stress are highly homologous to the second clade. KUP/HAK/KT, on the other hand, is a large family of high-affinity $\mathrm{K}^{+}$transporters that function in potassium acquisition and translocation from roots to shoots ${ }^{68,69}$, facilitate $\mathrm{K}^{+}$efflux from the vacuole to regulate osmotic adjustment, and some of them are involved in plant growth and development ${ }^{58,68,70}$. The $C$. pepo KUPs that were upregulated in salt-stressed $e t r 2 b$ leaf have a higher homology with Arabidopsis KUP6, an ABA responsive $\mathrm{K}^{+}$subfamily transporter that has a key role in osmotic adjustment and $\mathrm{K}^{+}$homoeostasis of guard cells ${ }^{58}$.

C. pepo etr $2 b$ plants induced the accumulation of metabolites, such as proline, total sugars (glucose, fructose, sucrose, and trehalose) and anthocyanins at both the roots and shoots under salt stress, which demonstrates that ethylene receptors and the subsequent ethylene or ABA signal transduction pathways are mediating the production of these osmolytes and therefore the osmotic adjustment of cells under salt stress ${ }^{71}$. These osmolytes can lower osmotic potential ${ }^{72}$, but can also act as stabilisers of proteins and cell components against ion toxicity and $\mathrm{NaCl}$-induced oxidative damage $\mathrm{P}^{71,73}$. Proline is perhaps the main salinity-related osmolyte, and is considered a biochemical marker of salt stress ${ }^{74}$. Exogenous proline treatments and transgenics plants with enhanced production of proline are more tolerant to salt, while mutants that are deficient in proline exhibited a limited growth and development under salt stress ${ }^{75,76}$. The biosynthesis of proline and other osmolytes is induced by ABA in different systems ${ }^{77}$, suggesting again that the enhanced response of mutant ethylene receptors of C. pepo to salt stress is likely mediated by ABA.

\section{Materials and methods \\ Plant material}

The ethylene receptor mutants analysed in this study, $e t r 1 b$, etr1a and etr $2 b$, were selected from a highthroughput screening of a Cucurbita pepo mutant collection by using the triple response of etiolated seedlings to ethylene ${ }^{41}$. In addition to their reduced triple response to ethylene, the three mutations convert female into hermaphrodite or male flowers, reducing or preventing self-fertilisation ${ }^{42,43}$. The mutants were therefore maintained in $\mathrm{BC}_{2} \mathrm{~S}_{1}$ segregating generations, obtained by crossing each mutant twice or more times with the background genotype MUC16, and then selfed. The mutations affect $C P E T R 1 B, C p E T R 1 A$, and $C p E T R 2 B$ genes; thus, the WT and mutant plants in segregating populations were selected by detecting the WT and etr $1 b$, etr $1 a$, and $e$ tr $2 b$ alleles using real-time PCR with TaqMan probes $^{42,43}$. DNA was isolated from the cotyledon of seedlings after the development of the first true leaf ( 5 or 
7 days after sowing, DAS) by using the CTAB protocol. The multiplex PCRs were done using the Bioline SensiFAST $^{\mathrm{TM}}$ Probe No-ROX Kit, a set of forward and reverse primers amplifying the polymorphic sequence, and two allele-specific probes descriptive of the SNP of interest. The WT probe was labelled with FAM dye, while the mutant probe was labelled with HEX reporter dye. BHQ1 quencher molecule was used in both probes (Supplementary Table S1).

\section{Seed germination under salinity stress}

Seed germination of WT and etr $1 b$, etrla, and $e t r 2 b$ was tested under salinity stress. Seeds were sterilised with a 5\% sodium hypochlorite solution for $10 \mathrm{~min}$ and rinsed in distilled water three times, before being incubated in $50 \mathrm{ml}$ Falcon tubes containing $25 \mathrm{ml}$ of distilled water (control) or $100 \mathrm{mM} \mathrm{NaCl}$ for $12 \mathrm{~h}$ at $25^{\circ} \mathrm{C}$ in darkness under continuous shaking. After the imbibition, the seeds were transferred to a dispositive designed to study seed germination (Supplementary Fig. S1). Seeds were placed in a foam strip between two pieces of filter paper and two panes of glass of $12 \times 20 \mathrm{~cm}$. This "sandwich glass" was secured with two clips and situated vertically in a recipient with water (control) or $100 \mathrm{mM} \mathrm{NaCl}$ solution for seeds to germinate and grow vertically. The sandwich glass with seeds was then incubated in a growth chamber in darkness at $24^{\circ} \mathrm{C}$ and $80 \% \mathrm{RH}$ for $55 \mathrm{~h}$. Three-hundred $\mathrm{BC}_{2} \mathrm{~S}_{1}$ seeds, segregating for each etr mutant, were germinated and grown using both water and salt in four independent experiments.

The germinated seeds were recorded every $2 \mathrm{~h}$ for $55 \mathrm{~h}$ through digital images that were processed using Image ${ }^{\circledR}$. Seeds were considered germinated when the seed coat was broken and primary root protrusion was visible (>1 mm). Germination initiation, time of germination at $50 \%$ of seeds, and average germination time were determined according to procedures described by Ranal and De Santana $^{78}$. Root elongation from both WT and ert mutants was assessed from seedling images at $48 \mathrm{~h}$ of initiating germination.

\section{Seedling and plantlets growth under salinity stress}

After germination, seeds were transplanted into 54 seedling trays filled with a mixture of perlite and coconut fibre (20-80\%), a substrate with low-cation exchange capacity. 150 seeds of each genotype (WT/WT and etr/etr), 75 germinated under salt stress and 75 germinated in water, were distributed in three independent experiments. Trays were incubated in a growth chamber in darkness at $24{ }^{\circ} \mathrm{C}$ and $80 \% \mathrm{RH}$ for $72 \mathrm{~h}$, and hypocotyl elongation was assessed in all plants. Control seedlings were irrigated with a nutritive Hoogland solution with a conductivity of $2 \mathrm{dS} / \mathrm{m}$; whereas, for those subjected to salt stress, the nutritive solution was supplemented with $35 \mathrm{mM}$ of NaCl , which increased its conductivity to $5 \mathrm{dS} / \mathrm{m}$.
Seedlings of each segregating population were then genotyped with Taqman probes, and $72 \mathrm{WT} / \mathrm{WT}$ and 72 etr/etr plants from each mutant family were transplanted into 11 pots containing the same substrate as previously, and grown for 20 additional days at $24{ }^{\circ} \mathrm{C}$ under long-day photoperiod ( $16 \mathrm{~h}$ light $/ 8 \mathrm{~h}$ dark) and $70 \% \mathrm{RH}$ in three independent experiments. Half of the plants (36) continued to be irrigated with the standard nutritive solution as previously, while the other half (36) were supplemented with $35 \mathrm{mM}$ of $\mathrm{NaCl}$. Leaf and root biomass were compared between each WT and ert mutant grown under both control and salinity conditions.

\section{Vegetative growth of WT and etr2b under salinity stress}

Although etr mutations affect female fertility and prevent selfing ${ }^{42,43}$, we were able to pollinate the mutant flowers several days prior to anthesis, thus forcing selffertilisation of the mutant plants and obtaining 100\% mutant offspring. This was only achieved in the etr $2 b$ mutant, which allowed the evaluation of a higher number of plants implementing the analysis of growth parameters in additional plant developmental stages, as well as biochemical and gene expression studies in this mutant. In this mutant family, separated WT and ert $2 b$ plants were cultivated for up to 45 days under either control or salt conditions following the protocol described in the previous section. The development of different growth parameters, including root length, plant height, and root and leaf fresh and dry weight, were compared between WT and $e r t 2 b$ at 5, 10, 20,30, and 45 DAS. Three independent replicates of ten plants each were analysed for each genotype and irrigation conditions at each developmental stage. At 45 DAS, plants were also used to analyse the effect of etr $2 b$ mutation on the content in micro- and macro-elements, the accumulation of stress metabolites, and the relative expression of stress-related genes.

\section{Evaluation of stress-associated metabolites in WT and etr2b plants}

The concentration of different stress metabolites, including proline, total carbohydrates and anthocyanins, was assessed in dry leaves and dry roots of WT and etr $2 b$ plants at 45 DAS under control and salinity stress conditions. All determinations were carried out in triplicate, each containing plant material from four plants.

Proline was determined through the ninhydrin method ${ }^{79}$ with minor modifications. $100 \mathrm{mg}$ of dry sample was incubated in a $2 \mathrm{ml}$ of ethanol $60 \%$ at $4{ }^{\circ} \mathrm{C}$ for $12 \mathrm{~h}$. $0.5 \mathrm{ml}$ of this solution was then mixed with $1 \mathrm{ml}$ of ninhydrin $1 \%$, dissolved in $60 \%$ acetic acid, and incubated at $95^{\circ} \mathrm{C}$ for $20 \mathrm{~min}$ at room temperature. Proline concentration was finally determined by spectrophotometry at $520 \mathrm{~nm}$, and expressed as $\mu \mathrm{mol} / \mathrm{g}$ DW. Total carbohydrates concentration was assessed by the phenol- 
sulphuric method ${ }^{80}$ with minor modifications. $100 \mathrm{mg}$ of dry sample was incubated in $5 \mathrm{ml}$ of ethanol $80 \%$ at $80^{\circ} \mathrm{C}$ for $1 \mathrm{~h}$, and $1 \mathrm{ml}$ of this solution was then mixed with $1 \mathrm{ml}$ of a solution of phenol $5 \%$ and $5 \mathrm{ml}$ of sulphuric acid 95-97\%. Total carbohydrates were determined at $490 \mathrm{~nm}$, and expressed as $\mathrm{mg} / \mathrm{g}$ DW. Anthocyanin content was measured according to Mancinelli ${ }^{81} .100 \mathrm{mg}$ of dry sample was incubated at $4{ }^{\circ} \mathrm{C}$ for $12 \mathrm{~h}$ in $3 \mathrm{ml}$ of a solution of ethanol acidified with $1 \%$ of $\mathrm{HCl} 37 \%$. The spectrophotometry measurements were done at 530 and $657 \mathrm{~nm}$, and the concentrations expressed as $\mu \mathrm{g} / \mathrm{g}$ DW. All spectrophotometric readings were performed on 96-well microplates using the BioTek ${ }^{\circledR}$ UV-Visible Epoch $^{\text {тм }}$ spectrophotometer.

\section{Comparison of micro- and macro-elements in WT and etr2b plants}

Micro- and macro-elements were measured in $5 \mathrm{~g}$ of dry leaves and roots coming from the same three samples for each genotype and salinity condition used in the determination of stress metabolites. The elemental measurements were carried out according to the standard protocols dictated by the International Organisation for Standardisation (ISO) (https://www.iso.org/home.html). Total nitrogen was measured through elemental analysis (ISO-13878), chloride was determined by fragmented flow analysis (ISO-15682), and the rest of macro- and micronutrients studied (phosphorus, potassium, calcium, magnesium, sulphur, iron, manganese, copper, zinc, boron, molybdenum, and sodium) were assessed by ICP-OES Spectrophotometry (ISO-11885).

\section{Assessment of gene expression by qRT-PCR in WT and etr2b plant}

The relative expression of different salt-stressassociated genes was assessed by quantitative reverse transcription (qRT)-PCR in WT and etr2b plants grown under control and salt conditions for 45 DAS. The analysis was performed in three biological replicates for each genotype and growing condition, each one derived from a pool of leaves from four plants. Total RNA was isolated from $1 \mathrm{~g}$ of leaves according to the protocol of the GeneJET Plant RNA Purification Kit (Thermo Fisher). RNA was reverted to cDNA with the ADNc RevertAid ${ }^{\mathrm{TM}}$ Kit (Thermo Fisher). The qRT-PCR was performed in $10 \mu \mathrm{l}$ total volume with $1 \times$ Top Green qPCR Super Mix (BioRad) in the CFX96 Touch Real-Time PCR Detection System Thermocycler (BioRad). The gene expression values were calculated using the $2^{-\Delta \Delta C T}$ method $^{82}$. EF1 $\alpha$ was used as the internal reference gene. Supplementary Table S2 shows the primers used for qRT-PCR reactions in each analysed gene.

\section{Phylogenetic analysis}

MEGA 10 software $^{83}$ was used to establish the phylogenetic relationships between C. pepo and Arabidopsis thaliana genes encoding for $\mathrm{Na}^{+}$and $\mathrm{K}^{+}$membrane transporters (KUPs, KEAs, NHXs, and HKTs), abscisic acid biosynthesis enzymes (NCEDs), and Calmodulinbinding receptor-like cytoplasmic kinases (CRCKs). Phylogenetic trees were performed using the Maximum Likelihood method based on the Poisson correction model, with 2000 bootstrap replicates. The protein sequences and information were obtained from the Arabidopsis Information Resource (https://www.arabidopsis. org/) and the Cucurbit Genomic Database (http:// cucurbitgenomics.org/).

\section{Statistical analysis}

Data were analysed for multiple comparisons by analysis of variance (ANOVA) using the statistical software Statgraphic Centurion XVIII. Differences between genotypes and treatments were separated by the least significant difference (LSD) at a significance level of $P \leq 0.05$.

\section{Acknowledgements}

This work has been supported by grant AGL2017-82885-C2-1-R, partly funded by the ERDF (European Regional Development Fund) and by the Spanish Ministry of Science and Innovation, and grant P12-AGR-1423, funded by Junta de Andalucía, Spain. G.C. and J.I. acknowledge FPU and FPI scholarship programmers from MEC, and C.M. is awarded a Hipatia post-doctoral grant.

\section{Conflict of interest}

The authors declare no competing interests.

Supplementary Information The online version contains supplementary material available at https://doi.org/10.1038/s41438-021-00508-z.

Received: 13 November 2020 Revised: 19 January 2021 Accepted: 24 January 2021

Published online: 01 April 2021

\section{References}

1. Zhang, P., Zhang, J. \& Chen, M. Economic impacts of climate change on agriculture: the importance of additional climatic variables other than temperature and precipitation. J. Environ. Econ. Manag. 83, 8-31 (2016).

2. Montanarella, L. et al (eds). Status of the World's Soil Resources (Swsr)-main Report. (FAO, 2015).

3. Isayenkov, S. V. \& Maathuis, F. J. M. Plant salinity stress: many unanswered questions remain. Front. Plant Sci. 10, 80 (2019).

4. Gull, A., Ahmad Lone, A. \& Ul Islam Wani, N. in Abiotic and Biotic Stress in Plants (ed. De Oliveira, A.) 3-9 (IntechOpen, 2019).

5. Demidchik, V. \& Maathuis, F. J. M. Physiological roles of nonselective cation channels in plants: from salt stress to signalling and development. N. Phytol. 175, 387-404 (2007).

6. Jiang, Z. et al. Plant cell-surface GIPC sphingolipids sense salt to trigger Ca2+ influx. Nature 572, 341-346 (2019).

7. Van Zelm, E., Zhang, Y. \& Testerink, C. Salt tolerance mechanisms of plants. Annu. Rev. Plant Biol. 71, 403-433 (2020).

8. Choi, W. G., Toyota, M., Kim, S. H., Hilleary, R. \& Gilroy, S. Salt stress-induced Ca2 + waves are associated with rapid, long-distance root-to-shoot signaling in plants. Proc. Natl Acad. Sci. USA 111, 6497-6502 (2014). 
9. Manishankar, P., Wang, N., Köster, P., Alatar, A. A. \& Kudla, J. Calcium signaling during salt stress and in the regulation of ion homeostasis. J. Exp. Bot. 69 4215-4226 (2018)

10. Sunarpi et al. Enhanced salt tolerance mediated by AtHKT1 transporterinduced $\mathrm{Na}+$ unloading from xylem vessels to xylem parenchyma cells. Plant J. 44, 928-938 (2005).

11. Pardo, J. M. Biotechnology of water and salinity stress tolerance. Curr. Opin. Biotechnol. 21, 185-196 (2010).

12. Rodríguez-Rosales, M. P. et al. Plant NHX cation/proton antiporters. Plant Signal. Behav. 4, 265-276 (2009).

13. Bassil, E. et al. The Arabidopsis $\mathrm{Na}+/ \mathrm{H}+$ antiporters $\mathrm{NHX} 1$ and $\mathrm{NHX} 2$ control vacuolar $\mathrm{pH}$ and $\mathrm{K}+$ homeostasis to regulate growth, flower development, and reproduction. Plant Cell 23, 3482-3497 (2011).

14. Reguera, $M$. et al. $\mathrm{pH}$ regulation by NHX-type antiporters is required for receptor-mediated protein trafficking to the vacuole in Arabidopsis. Plant Cell 27, 1200-1217 (2015).

15. Apse, M. P., Aharon, G. S., Snedden, W. A. \& Blumwald, E. Salt tolerance conferred by overexpression of a vacuolar $\mathrm{Na}+/ \mathrm{H}+$ antiport in Arabidopsis. Science (80-) 285, 1256-1258 (1999).

16. Zhang, H. X. \& Blumwald, E. Transgenic salt-tolerant tomato plants accumulate salt in foliage but not in fruit. Nat. Biotechnol. 19, 765-768 (2001).

17. Mian, A. et al. Over-expression of an $\mathrm{Na}+-$ and $\mathrm{K}+-$ permeable $\mathrm{HKT}$ transporter in barley improves salt tolerance. Plant J. 68, 468-479 (2011).

18. Slama, I., Abdelly, C., Bouchereau, A., Flowers, T. \& Savouré, A. Diversity, distribution and roles of osmoprotective compounds accumulated in halophytes under abiotic stress. Ann. Bot. 115, 433-447 (2015).

19. Munns, R. \& Gilliham, M. Salinity tolerance of crops-what is the cost? N. Phytol. 208, 668-673 (2015)

20. Niu, M. et al. Root respiratory burst oxidase homologue-dependent $\mathrm{H}_{2} \mathrm{O} 2$ production confers salt tolerance on a grafted cucumber by controlling $\mathrm{Na}+$ exclusion and stomatal closure. J. Exp. Bot. 69, 3465-3476 (2018).

21. Keunen, E., Peshev, D., Vangronsveld, J., Van Den Ende, W. \& Cuypers, A. Plant sugars are crucial players in the oxidative challenge during abiotic stress: extending the traditional concept. Plant. Cell Environ. 36, 1242-1255 (2013).

22. Lockhart, J. Salt of the earth: ethylene promotes salt tolerance by enhancing $\mathrm{Na} / \mathrm{K}$ homeostasis. Plant Cell 25, 3150 (2013).

23. Verma, R. K. et al. Overexpression of ABA receptor PYL10 gene confers drought and cold tolerance to indica rice. Front. Plant Sci. 10, 1488 (2019).values were calculated

24. Tao, J. J. et al. The role of ethylene in plants under salinity stress. Front. Plant Sci. 6, 1-12 (2015).

25. Arraes, F. B. et al. Implications of ethylene biosynthesis and signaling in soybean drought stress tolerance. BMC Plant Biol. 15, 1-20 (2015).

26. Albacete, A. et al. Rootstock-mediated changes in xylem ionic and hormonal status are correlated with delayed leaf senescence, and increased leaf area and crop productivity in salinized tomato. Plant Cell Environ. 32, 928-938 (2009).

27. Riyazuddin, R. et al. Ethylene: a master regulator of salinity stress tolerance in plants. Biomolecules 10, 959 (2020).

28. Peng, J. et al. Salt-induced stabilization of EIN3/EIL1 confers salinity tolerance by deterring ROS accumulation in Arabidopsis. PLoS Genet. 10, e1004664 (2014).

29. Dong, $\mathrm{H}$. et al. Loss of ACS7 confers abiotic stress tolerance by modulating ABA sensitivity and accumulation in Arabidopsis. J. Exp. Bot. 62, 4875-4887 (2011).

30. Chen, D. et al. A wheat aminocyclopropane-1-carboxylate oxidase gene, TaACO1, negatively regulates salinity stress in Arabidopsis thaliana. Plant Cell Rep. 33, 1815-1827 (2014).

31. Li, C. H. et al. The receptor-like kinase SIT1 mediates salt sensitivity by activating MAPK3/6 and regulating ethylene homeostasis in rice. Plant Cell 26, 2538-2553 (2014)

32. Yang, C., Lu, X., Ma, B., Chen, S. Y. \& Zhang, J. S. Ethylene signaling in rice and Arabidopsis: conserved and diverged aspects. Mol. Plant 8, 495-505 (2015).

33. Ju, C. \& Chang, C. Mechanistic insights in ethylene perception and signal transduction. Plant Physiol. 169, 85-95 (2015).

34. Binder, B. M., Chang, C. \& Schaller, G. E. in Annual Plant Reviews. Vol. 44 (ed. McManus, M. T.) 117-145 (Wiley-Blackwell, 2012)

35. Hua, J. \& Meyerowitz, E. M. Ethylene responses are negatively regulated by a receptor gene family in Arabidopsis thaliana. Cell 94, 261-271 (1998).

36. Wilson, R. L., Kim, H., Bakshi, A. \& Binder, B. M. The ethylene receptors ETHYLENE RESPONSE1 and ETHYLENE RESPONSE2 have contrasting roles in seed germination of Arabidopsis during salt stress. Plant Physiol. 165, 1353-1366 (2014).

37. Wilson, R. L., Bakshi, A. \& Binder, B. M. Loss of the ETR1 ethylene receptor reduces the inhibitory effect of far-red light and darkness on seed germination of Arabidopsis thaliana. Front. Plant Sci. 5, 433 (2014).

38. Bakshi, A. et al. Identification of regions in the receiver domain of the ETHYLENE RESPONSE1 ethylene receptor of Arabidopsis important for functional divergence. Plant Physiol. 169, 219-232 (2015).

39. Bakshi, A. et al. Ethylene receptors signal via a noncanonical pathway to regulate abscisic acid responses. Plant Physiol. 176, 910-929 (2018).

40. Wang, Y. et al. Ethylene enhances seed germination and seedling growth under salinity by reducing oxidative stress and promoting chlorophyll content via ETR2 pathway. Front. Plant Sci. 11, 1066 (2020).

41. García, A. et al. Phenomic and genomic characterization of a mutant platform in Cucurbita pepo. Front. Plant Sci. 9, 1049 (2018).

42. García, A. et al. The ethylene receptors CpETR1A and CpETR2B cooperate in the control of sex determination in Cucurbita pepo. J. Exp. Bot. 71, 154-167 (2020).

43. García, A., Aguado, E., Garrido, D., Martínez, C. \& Jamilena, M. Two androecious mutations reveal the crucial role of ethylene receptors in the initiation of female flower development in Cucurbita pepo. Plant J. 103, 1548-1560 (2020).

44. Montero-Pau, J. et al. De novo assembly of the zucchini genome reveals a whole-genome duplication associated with the origin of the Cucurbita genus. Plant Biotechnol. J. 16, 1161-1171 (2018).

45. Zhao, X. C. \& Schaller, G. E. Effect of salt and osmotic stress upon expression of the ethylene receptor ETR1 in Arabidopsis thaliana. FEBS Lett. 562, 189-192 (2004).

46. Yang, L., Zu, Y. G. \& Tang, Z. H. Ethylene improves Arabidopsis salt tolerance mainly via retaining $\mathrm{K}+$ in shoots and roots rather than decreasing tissue $\mathrm{Na}+$ content. Environ. Exp. Bot. 86, 60-69 (2013).

47. Gharbi, E. et al. Inhibition of ethylene synthesis reduces salt-tolerance in tomato wild relative species Solanum chilense. J. Plant Physiol. 210, 24-37 (2017).

48. Chiwocha, S. D. et al. The etr1-2 mutation in Arabidopsis thaliana affects the abscisic acid, auxin, cytokinin and gibberellin metabolic pathways during maintenance of seed dormancy, moist-chilling and germination. Plant J. 42, 35-48 (2005).

49. Wang, Y., Wang, T., Li, K. \& Li, X. Genetic analysis of involvement of ETR1 in plant response to salt and osmotic stress. Plant Growth Regul. 54, 261-269 (2008).

50. Li, Z., Peng, J., Wen, X. \& Guo, H. ETHYLENE-INSENSITIVE3 is a senescenceassociated gene that accelerates age-dependent leaf senescence by directly repressing miR164 transcription in Arabidopsis. Plant Cell 25, 3311-3328 (2013).

51. Beaudoin, N., Serizet, C., Gosti, F. \& Giraudat, J. Interactions between abscisic acid and ethylene signaling cascades. Plant Cell 12, 1103-1115 (2000).

52. Bleecker, A. B., Estelle, M. A., Somerville, C. \& Kende, H. Insensitivity to ethylene conferred by a dominant mutation in Arabidopsis thaliana. Science. (80-.) 241, 1086-1089 (1988)

53. Grbic, V. \& Bleecker, A. B. Ethylene regulates the timing of leaf senescence in Arabidopsis. Plant J. 8, 595-602 (1995).

54. Tholen, D., Voesenek, L. A. C. J. \& Poorter, H. Ethylene insensitivity does not increase leaf area or relative growth rate in Arabidopsis, Nicotiana tabacum, and Petunia x hybrida. Plant Physiol. 134, 1803-1812 (2004).

55. Cao, W. H. et al. in Advances in Plant Ethylene Research (eds Klee, $\mathrm{H}$. et al) 333-339 (Springer, 2007)

56. Kazan, K. Diverse roles of jasmonates and ethylene in abiotic stress tolerance Trends Plant Sci. 20, 219-229 (2015)

57. DeFalco, T. A., Bender, K. W. \& Snedden, W. A. Breaking the code: Ca2+ sensors in plant signalling. Biochem. J. 425, 27-40 (2010)

58. Osakabe, Y. et al. Osmotic stress responses and plant growth controlled by potassium transporters in Arabidopsis. Plant Cell 25, 609-624 (2013).

59. Verslues, P. E. \& Bray, E. A. Role of abscisic acid (ABA) and Arabidopsis thaliana ABA-insensitive loci in low water potential-induced ABA and proline accumulation. J. Exp. Bot. 57, 201-212 (2006).

60. Leidi, E. O. et al. The AtNHX1 exchanger mediates potassium compartmentation in vacuoles of transgenic tomato. Plant J. 61, 495-506 (2010).

61. Fukuda, A., Nakamura, A., Hara, N., Toki, S. \& Tanaka, Y. Molecular and functional analyses of rice $\mathrm{NHX}$-type $\mathrm{Na}+/ \mathrm{H}+$ antiporter genes. Planta 233, 175-188 (2011). 
62. Berthomieu, P. et al. Functional analysis of AtHKT1 in Arabidopsis shows that $\mathrm{Na}+$ recirculation by the phloem is crucial for salt tolerance. EMBO J. 22 2004-2014 (2003).

63. Garciadeblás, B., Senn, M. E., Bañuelos, M. A. \& Rodríguez-Navarro, A. Sodium transport and HKT transporters: the rice model. Plant J. 34, 788-801 (2003).

64. Horie, T., Hauser, F. \& Schroeder, J. I. HKT transporter-mediated salinity resistance mechanisms in Arabidopsis and monocot crop plants. Trends Plant Sci. 14, 660-668 (2009).

65. Kobayashi, N. I. et al. OsHKT1;5 mediates $\mathrm{Na}+$ exclusion in the vasculature to protect leaf blades and reproductive tissues from salt toxicity in rice. Plant $\mathrm{J}$. 91, 657-670 (2017).

66. Kunz, H. H. et al. Plastidial transporters KEA1, -2, and -3 are essential for chloroplast osmoregulation, integrity, and $\mathrm{pH}$ regulation in Arabidopsis. Proc. Natl Acad. Sci. USA 111, 7480-7485 (2014).

67. Zhu, $\mathrm{X}$. et al. $\mathrm{K}+$ efflux antiporters 4,5 , and 6 mediate $\mathrm{pH}$ and $\mathrm{K}+$ homeostasis in endomembrane compartments. Plant Physiol. 178, 1657-1678 (2018).

68. Yang, T. et al. The role of a potassium transporter OsHAK5 in potassium acquisition and transport from roots to shoots in rice at low potassium supply levels. Plant Physiol. 166, 945-959 (2014).

69. Han, M., Wu, W., Wu, W. H. \& Wang, Y. Potassium transporter KUP7 is involved in $\mathrm{K}+$ acquisition and translocation in Arabidopsis root under $\mathrm{K}+$-limited conditions. Mol. Plant. 9, 437-446 (2016).

70. Grabov, A. Plant KT/KUP/HAK potassium transporters: single family-multiple functions. Ann. Bot. 99, 1035-1041 (2007).

71. Nahar, K., Hasanuzzaman, M. \& Fujita, M. in Osmolytes and Plants Acclimation to Changing Environment: Emerging Omics Technologies (eds lqbal, N., Nazar, R. \& Khan, N. A.) 37-68 (Springer, 2015).

72. Argiolas, A., Puleo, G. L., Sinibaldi, E. \& Mazzolai, B. Osmolyte cooperation affects turgor dynamics in plants. Sci. Rep. 6, 1-8 (2016).
73. Gharsallah, C., Fakhfakh, H., Grubb, D. \& Gorsane, F. Effect of salt stress on ion concentration, proline content, antioxidant enzyme activities and gene expression in tomato cultivars. AoB Plants 8, plw055 (2016).

74. Hayat, $\mathrm{S}$. et al. Role of proline under changing environments: a review. Plant Signal. Behav. 7, 1456-1466 (2012).

75. Khedr, A. H. A., Abbas, M. A., Wahid, A. A. A., Quick, W. P. \& Abogadallah, G. M. Proline induces the expression of salt-stress-responsive proteins and may improve the adaptation of Pancratium maritimum L. to salt-stress. J. Exp. Bot. 54, 2553-2562 (2003).

76. Simon-Sarkadi, L., Kocsy, G., Várhegyi, Á., Galiba, G. \& De Ronde, J. A. Stressinduced changes in the free amino acid composition in transgenic soybean plants having increased proline content. Biol. Plant. 50, 793-796 (2006).

77. Yu, Z. et al. How plant hormones mediate salt stress responses. Trends Plant Sci. 25, 1117-1130 (2020).

78. Ranal, M. A. \& De Santana, D. G. How and why to measure the germination process? Rev. Bras. Bot. 29, 1-11 (2006).

79. Abrahám, E., Hourton-Cabassa, C., Erdei, L. \& Szabados, L. Methods for determination of proline in plants. Methods Mol. Biol. 639, 317-331 (2010).

80. Chow, P. S. \& Landhäusser, S. M. A method for routine measurements of total sugar and starch content in woody plant tissues. Tree Physiol. 24, 1129-1136 (2004).

81. Mancinelli, A. L. Interaction between light quality and light quantity in the photoregulation of anthocyanin production. Plant Physiol. 92, 1191-1195 (1990).

82. Livak, K. J. \& Schmittgen, T. D. Analysis of relative gene expression data using real-time quantitative PCR and the $2^{-\triangle C T}$ method. Methods 25, 402-408 (2001).

83. Kumar, S., Stecher, G., Li, M., Knyaz, C. \& Tamura, K. MEGA X: molecular evolutionary genetics analysis across computing platforms. Mol. Biol. Evol. 35 1547-1549 (2018). 